Tropical Journal of Pharmaceutical Research July 2020; 19 (7): 1503-1509

ISSN: $1596-5996$ (print); 1596-9827 (electronic)

(C) Pharmacotherapy Group, Faculty of Pharmacy, University of Benin, Benin City, 300001 Nigeria

Available online at http://www.tjpr.org

Original Research Article

http://dx.doi.org/10.4314/tjpr.v19i7.24

\title{
Development and validation of spectrophotometric and spectrofluorimetric methods for determination of cilnidipine
}

\author{
Safwan M Fraihat ${ }^{1 *}$, Hatim S Al Khatib² \\ ${ }^{1}$ Department of Chemistry, School of Science, The University of Jordan 11942, Amman-Jordan, ${ }^{2}$ Department of Pharmaceutics, \\ School of Pharmacy, The University of Jordan 11942, Amman-Jordan
}

${ }^{*}$ For correspondence: Email: s.fraihat@ju.edu.jo; Tel: 00962779852481

Sent for review: 26 November 2019

Revised accepted: 18 June 2020

\begin{abstract}
Purpose: To develop simple and reliable quantitative methods for the determination of cilnidipine (CLD) in pharmaceutical tablets.

Methods: Two simple and sensitive methods (spectrophotometric and spectrofluorimetric) were developed for the determination of cilnidipine (CLD) in pure form and in a pharmaceutical preparation. Spectrophotometric method $(A)$ is based on oxidation of CLD with a known excess amount of $N$ bromosuccinamide (NBS) in acidic medium, followed by addition of methyl orange indicator and absorbance measurement at $510 \mathrm{~nm}$. The spectrofluorimetric method (B) is based on oxidation of CLD to cerium (IV), followed by measurement of fluorescence emission of Ce (III) at $350 \mathrm{~nm}$. Factors that affect the performance of the two methods were studied and optimized.

Results: The spectrophotometric and spectrofluorimetric procedures were successfully used for measuring CLD levels in pharmaceutical dosage form, in the ranges of $2.0-25.0$ and $0.25-11.2 \mu \mathrm{g} / \mathrm{mL}$, at detection limits of 1.05 and $0.13 \mu \mathrm{g} / \mathrm{mL}$, respectively. There were no significant differences between the proposed methods and a standard reference method $(p<0.05)$.

Conclusion: The developed methods provide simple and reliable procedures for quantitative measurement of CLD in bulk and tablet forms.
\end{abstract}

Keywords: Cilnidipine, Oxidation, Spectrophotometric, Spectrofluorimetric, Drug formulation

\begin{abstract}
This is an Open Access article that uses a fund-ing model which does not charge readers or their institutions for access and distributed under the terms of the Creative Commons Attribution License (http://creativecommons.org/licenses/by/4.0) and the Budapest Open Access Initiative (http://www.budapestopenaccessinitiative.org/read), which permit unrestricted use, distribution, and reproduction in any medium, provided the original work is properly credited.

Tropical Journal of Pharmaceutical Research is indexed by Science Citation Index (SciSearch), Scopus, International Pharmaceutical Abstract, Chemical Abstracts, Embase, Index Copernicus, EBSCO, African Index Medicus, JournalSeek, Journal Citation Reports/Science Edition, Directory of Open Access Journals (DOAJ), African Journal Online, Bioline International, Open-J-Gate and Pharmacy Abstracts
\end{abstract}

\section{INTRODUCTION}

Cilnidipine (CLD) (Figure 1) is a unique 1,4dihydropyridine derivative and $\mathrm{Ca}^{2+}$ channel blocking agent with potent inhibitory effects on Ltype and $\mathrm{N}$-type voltage-dependent calcium channels [1]. Cilnidipine (CLD) is a fourthgeneration 1,4-dihydropyridine derivative used in the treatment of hypertension. It depresses sympathetic nervous system activity and reduces the associated adverse effects, with good therapeutic outcome. It has some advantages over old generation treatments [2].

There are limited analytical procedures for quantification of CLD in its pure and tablet forms. These methods are UV-VIS spectrophotometry [3-6], HPLC [7-10], and electrochemistry [11]. 
Spectrophotometric methods have many advantages over other methods, in terms of simplicity, fair sensitivity and relative cheapness. This research was designed to evolve easy and selective procedures based on spectrophotometry and spectrofluorimetry for the determination of CLD in drug preparations without laborious procedures such as extraction and derivatization steps.<smiles>COCCOC(=O)C1=C(C)NC(C)=C(C(=O)OC/C=C/c2ccccc2)C1c1cccc([N+](=O)[O-])c1</smiles>

Figure 1: Cilnidipine structure

To the knowledge of the authors, there are no reported spectrofluorimetric methods for the determination of CLD in pure and pharmaceutical preparations. The first method was an indirect spectrophotometric procedure in which CLD was oxidized with excess amount of $\mathrm{N}$ bromosuccinamide (NBS) in acidic medium. Then, methyl orange indicator was used to determine the amount of unreacted NBS by measuring the absorbance of residual dye at 510 $\mathrm{nm}$, which is directly proportional to the original amount of the drug. In the spectrofluorimetric method, the drug was oxidized with cerium (IV) in acidic medium, and the resultant $\mathrm{Ce}$ (III) was monitored by measuring its emission fluorescence at $350 \mathrm{~nm}$ following excitation at $254 \mathrm{~nm}$. Both methods were utilized for construction of standard calibration curves for the determination of the concentration of CLD either in pure or pharmaceutical tablets. The oxidation reaction conditions were optimized and validated for sensitivity, precision, and accuracy. The proposed methods can be readily used without the need for expensive apparatus and complicated steps.

\section{EXPERIMENTAL}

\section{Materials}

Cilnidipine hydrochloride (CLD) in its pure form and pharmaceutical preparation (Cilicar) containing $20 \mathrm{mg}$ of active drug were purchased from J.B. Pharmaceutical and Chemicals Ltd. Analytical-grade reagents and chemicals were used, and were procured from Scharalu.

\section{Preparation of solutions}

Cilnidipine: A $100 \mu \mathrm{g} / \mathrm{mL}$ solution of CLD was made in acetonitrile. Using micropipettes, working solutions were prepared via appropriate dilutions in 10-mL calibrated flasks.

N-Bromosuccinamide: A $0.20-\mathrm{mg} / \mathrm{mL}$ solution of $\mathrm{N}$-bromosuccinamide was freshly prepared in double-distilled water.

Methyl orange: A $0.2-\mathrm{mg} / \mathrm{mL}$ solution of methyl orange solution was prepared in double-distilled water.

Cerium ammonium sulfate: A $20-\mathrm{mg} / \mathrm{mL}$ solution of $\mathrm{Ce}$ (IV) was made by dissolving 2.0 grams of cerium ammonium sulfate in $500 \mathrm{~mL}$ of $0.25 \mathrm{M}$ sulfuric acid.

Hydrochloric acid stock solution $(5.0 \mathrm{M})$ was used.

\section{Instrumentation and techniques}

Absorbance measurements were made using CARY UV-VIS spectrophotometer (CARY model) and $1-\mathrm{cm}$ glass cells. Fluorescence spectra measurements were done on an Agilent Technology, Cary Eclipse, G9800AA model Luminescence spectrometer (Australia) equipped with a xenon arc lamp. The slit width for excitation and emission measurements was set at $5.0 \mathrm{~nm}$, and readings were taken with a 1.0$\mathrm{cm}$ internal diameter quartz cell at $25.0^{\circ} \mathrm{C}$.

\section{General procedures}

Method A (spectrophotometric method): Aliquots of standard CLD solution $(100 \mu \mathrm{g} / \mathrm{mL})$ were accurately transferred to a series of $10-\mathrm{mL}$ volumetric flasks and made up to final concentrations in the range of $1-50 \mu \mathrm{g} / \mathrm{mL}$. Then, $1.0 \mathrm{~mL}$ of $\mathrm{NBS}$ and $2.0 \mathrm{~mL}$ of $5 \mathrm{M} \mathrm{HCl}$ solutions were added to each flask, shaken and left to stand at room temperature for $40 \mathrm{~min}$. Thereafter, $1.0 \mathrm{~mL}$ of $0.2 \mathrm{mg} / \mathrm{mL} \mathrm{MO}$ dye solution was added to each flask, and the resulting solution were shaken, followed by absorbance reading at $510 \mathrm{~nm}$.

Method B (Spectrofluorimetric method): Aliquots of standard CLD solution $(100 \mu \mathrm{g} / \mathrm{mL})$ were transferred into a series of $10-\mathrm{mL}$ volumetric flasks and made up to final concentrations ranging from 0.10 to $25 \mu \mathrm{g} / \mathrm{mL}$. This was followed by the addition of $1.0 \mathrm{~mL}$ of $\mathrm{Ce}$ (IV) reagent solution to each flask. Then, the volume of liquid in each flask was adjusted to $5.0 \mathrm{~mL}$ with water, and each flask was kept in a shaking water bath at $40^{\circ} \mathrm{C}$ for $1 \mathrm{~h}$. Thereafter, the solutions were cooled to room temperature $\left(25^{\circ}\right.$ $\mathrm{C})$, and their fluorescence emission intensities 
was read at excitation and emission wavelengths of $254 \mathrm{~nm}$ and $350 \mathrm{~nm}$, respectfully.

\section{Preparation of tablet}

Ten 20-mg CLD tablets were accurately weighed and finely powdered. Then, an amount of powder equivalent to $10 \mathrm{mg}$ CLD was subjected to dissolution in acetonitrile $(10 \mathrm{~mL})$, and the solution was filtered. Aliquots of the clear filtrate were analyzed using each of the developed methods.

\section{RESULTS}

For both methods being developed, optimization of reaction conditions including reagent concentrations, diluents, temperature and time was done. Method validation in terms of $\mathrm{ISH}$ guidelines including accuracy, precision, sensitivity, selectivity, range and linearity was performed. The reaction conditions for the two developed methods were optimized with respect to reagent concentration, diluent, temperature and reaction duration (time). In addition, method validation was carried out in line with ISH guidelines for accuracy, precision, sensitivity, selectivity, range and linearity.

\section{Optimized reaction conditions}

Factors that affect oxidation reactions were studied and optimized. These include reagent concentration and duration of reaction.

\section{Spectrophotometric method}

The effect of different variables that affect oxidation reactions were studied carefully, to obtain maximum absorbance at low drug concentration. These conditions included:

\section{(i) Effect of NBS volume}

Different volumes of NBS solution $(0.20 \mathrm{mg} / \mathrm{mL})$ were used, while keeping the concentration of CLD at $5.0 \mu \mathrm{g} / \mathrm{mL}$, in addition to maintaining constant, $1 \mathrm{~mL}$ of $\mathrm{MO}(0.20 \mathrm{mg} / \mathrm{mL})$ and $1.0 \mathrm{~mL}$ of $5 \mathrm{M} \mathrm{HCl}$. As shown in Figure 2, it was found that $1.5 \mathrm{~mL}$ of NBS resulted in maximum absorbance.

\section{(ii) Type and concentration of acid}

Different acids $\left(\mathrm{HCl}, \mathrm{H}_{2} \mathrm{SO}_{4}\right.$ and $\left.\mathrm{H}_{3} \mathrm{PO}_{4}\right)$ were used at same concentrations. It was found that $\mathrm{HCl}$ resulted in faster color development than any of the other acids used. The optimum amount of $5 \mathrm{M} \mathrm{HCl}$ used was $1.0 \mathrm{~mL}$.

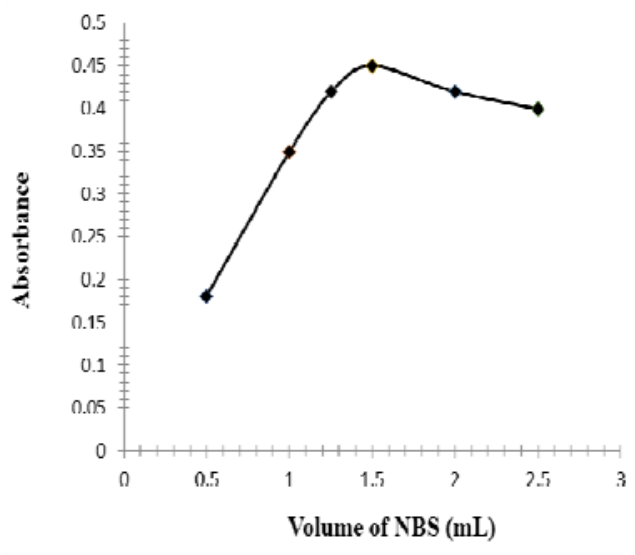

Figure 2: Effect of volume of NBS $(0.2 \mathrm{mg} / \mathrm{mL})$ added to CLD $(5 \mu \mathrm{g} / \mathrm{mL})$ on absorbance

\section{(iii) Effect of volume of methyl orange}

The optimum volume of MO was determined by varying its volume from 0.5 to $2.5 \mathrm{~mL}$, while using fixed amount of CLD at $5.0 \mu \mathrm{g} / \mathrm{mL}, 1.0 \mathrm{~mL}$ of NBS solution and $1 \mathrm{~mL}$ of $5 \mathrm{M} \mathrm{HCl}$.

\section{(iv) Temperature and time}

The progress of reaction was monitored by measuring absorbance at $510 \mathrm{~nm}$ between 5 and $60 \mathrm{~min}$. at $25{ }^{\circ} \mathrm{C}$. It was discovered that absorbance became stable after about $30 \mathrm{~min}$ at $25{ }^{\circ} \mathrm{C}$. Therefore, 30-min standing time was selected for all measurements. Color was stable for about $180 \mathrm{~min}$.

\section{Spectrofluorimetric method}

The excitation and emission spectrum shown in Figure 3 was used to select suitable wavelengths for the determination of CLD from the emission wavelength at $354 \mathrm{~nm}$.

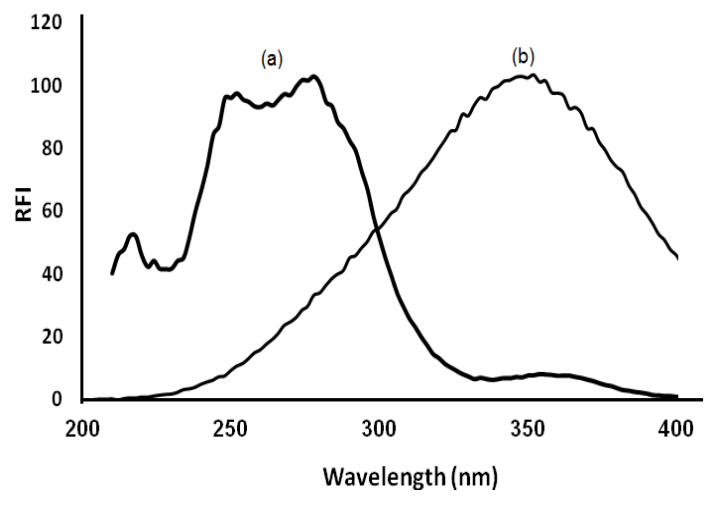

Figure 3: Excitation (a) and emission (b) spectra of $1.0 \mu \mathrm{g} / \mathrm{mL}$ CLD after oxidation with Ce (IV) according to calibration curve procedure for method $B$ 


\section{(i) Effect of $\mathrm{Ce}$ (IV) volume}

An optimum volume of $6.3 \times 10^{-3} \mathrm{M}$ cerium (IV) solution was obtained by increasing the volume of $\mathrm{Ce}$ (IV) solution used from 0.2 to $2.0 \mathrm{~mL}$, as shown in Figure 4. It is clear that peak fluorescence intensity was reached using about $1.0 \mathrm{~mL}$ of the oxidant, with fixed amount of CLD.

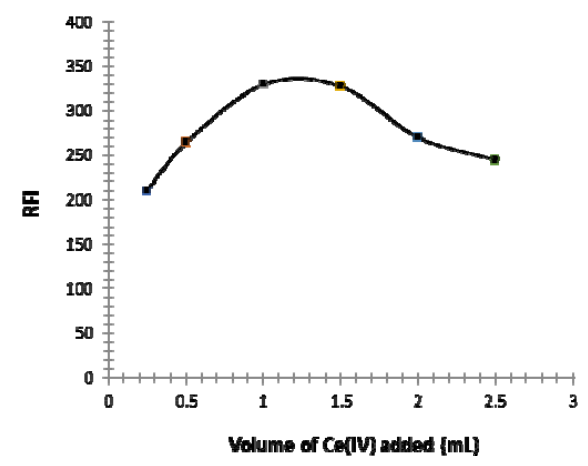

Figure 4: Effect of added volume of $6.3 \times 10^{-3} \mathrm{M} \mathrm{Ce}$ (IV) to CLD $(5.0 \mu \mathrm{g} / \mathrm{mL})$ solution

\section{(ii) Temperature and time}

The reaction was monitored at different temperatures $\left(25,40\right.$ and $\left.60{ }^{\circ} \mathrm{C}\right)$ at different durations (5 - $40 \mathrm{~min}$ ), after which the solutions were cooled to 25 before measuring the fluorescence intensities. It was found that heating temperature of $40{ }^{\circ} \mathrm{C}$ after 60 min gave the highest response values and stability.

\section{(iii) Diluting solvent}

Different diluting solvents (water, methanol, ethanol, acetonitrile, dioxan and cyclohexane) were used. As shown in Figure 5, acetonitrile provided the maximum fluorescence intensity and the highest stability. It was therefore chosen as the optimum solvent.

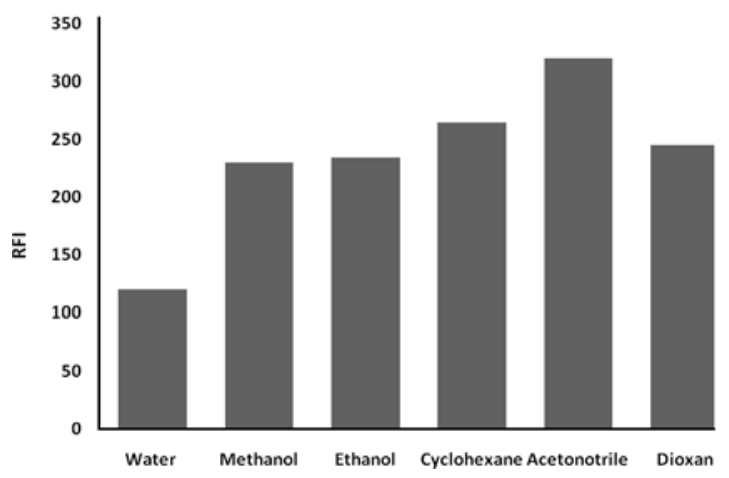

Figure 5: Influence of diluting solvents on RFI of CLD $(5.0 \mu \mathrm{g} / \mathrm{mL})$ solution
Validated methods

\section{Linearity, range and sensitivity}

Different CLD concentrations were prepared and applied in both methods. For the spectrophotometric method, a linear plot of CLD concentration against absorbance of $\mathrm{MO}$ dye at $510 \mathrm{~nm}$ produced a correlation coefficient $\left(R^{2}\right)$ of 0.992). For the spectrofluorimetric method, a plot of CLD concentration against relative fluorescence intensities (RFI) was linear within the range of $0.25-11.2 \mu \mathrm{g} / \mathrm{mL}$, with a correlation coefficient $\left(R^{2}\right)$ of 0.994$)$. The calibration plots of the two methods are shown in Figure 6.
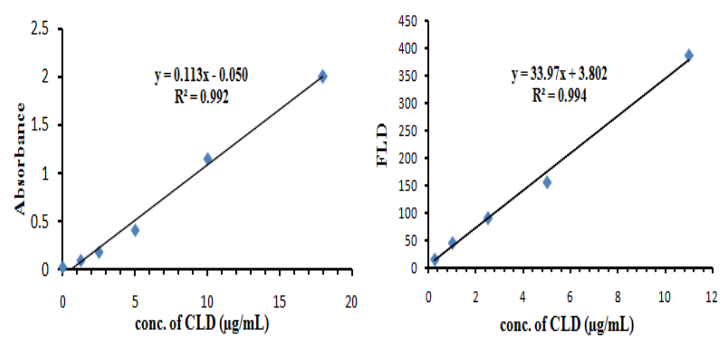

Figure 6: Standard curves. Spectrophotometric procedure (left), and spectrofluorimetric procedure (right)

From the data shown in Table 1, it is clear that both methods have excellent correlations and good concentration ranges.

The sensitivities were measured in terms of limit of detection (LOD) and limit of Quantitation (LOQ) which were determined in line with $\mathrm{ICH}$ guidelines as in Eqs 1 and 2 [16] (Table 1).
$L O D=\frac{3.3 \times \sigma}{S}$

and

$L O Q=\frac{10 X \sigma}{S}$ where $\sigma$ represents SD of $y$-intercept of regression lines, and $S$ is gradient of standard curve.

\section{Accuracy and precision}

Determinations were done with 3 concentrations of CLD to measure inter-day precision of five replicates for six days using the developed procedures. The RSDs were between $0.87-1.4$ $\%$, with high \% recovery for inter-day analysis, indicating high precision and accuracy of the procedures. These results are presented in Table 2. 
Table 1: Data showing analytical performance of the methods

\begin{tabular}{|c|c|c|}
\hline Parameter & Method A & Method B \\
\hline $\begin{array}{l}\text { Linear range } \\
(\mu \mathrm{g} / \mathrm{mL})\end{array}$ & $2.0-25.0$ & $0.25-11.2$ \\
\hline Wavelength (nm) & 510 & $\begin{array}{c}\lambda(\text { excitation }) \\
250\end{array}$ \\
\hline $\begin{array}{l}\text { Correlation } \\
\text { coefficient }\end{array}$ & 0.992 & 0.994 \\
\hline Slope (b) & 0.113 & 39. 97 \\
\hline Intercept (a) & 0.05 & 3.9 \\
\hline $\begin{array}{l}\text { SD of the intercept } \\
\text { (SDa) }\end{array}$ & 0.021 & 0.3 \\
\hline $\mathrm{LOD}^{\mathrm{a}}(\mu \mathrm{g} / \mathrm{mL})$ & 1.05 & 0.13 \\
\hline $\mathrm{LOQ}^{\mathrm{b}}(\mu \mathrm{g} / \mathrm{mL})$ & 3.17 & 0.41 \\
\hline
\end{tabular}

\section{Selectivity studies}

The selectivity of each developed method was measured through analyses of placebo and synthetic admixture. The blank was prepared from acacia, starch, $\mathrm{OH}$-cellulose and $\mathrm{Na}$ alginate which were thoroughly mixed and made into tablets which were then analyzed. Signals obtained from the two methods with respect to the blank were nearly equivalent to those of the reagent blank, indicating that there were no appreciable interferences due to excipients.

Table 2: Recovery data for inter-day precision and accuracy

\begin{tabular}{lcccc}
\hline Method & $\begin{array}{c}\text { CLD } \\
\text { taken } \\
(\boldsymbol{\mu} \mathbf{g} / \mathbf{m L})\end{array}$ & $\begin{array}{c}\text { CLD } \\
\text { found } \\
(\boldsymbol{\mu} \mathbf{g} / \mathbf{m L})\end{array}$ & $\begin{array}{c}\text { RSD } \\
(\%)\end{array}$ & $\begin{array}{c}\text { Recovery } \\
(\%)\end{array}$ \\
\hline $\mathrm{A}$ & 4.0 & 3.9 & 1.35 & 97.5 \\
& 8.0 & 7.6 & 1.24 & 95.0 \\
$\mathrm{~B}$ & 12.0 & 12.1 & 1.65 & 100.8 \\
& 1.0 & 1.0 & 0.87 & 100.5 \\
& 3.0 & 2.9 & 1.12 & 96.7 \\
& 8.0 & 7.9 & 1.45 & 98.8 \\
\hline
\end{tabular}

\section{Application to drug formulation}

The proposed methods were applied successfully to only one marketed product
(Cilicar tablet) due to the difficulties of obtaining other brands of CLD because the drug is not approved in many countries. The results, which showed high accuracy and precision using three different concentration levels of CLD, are summarized in Table 3.

Table 3: Precision and accuracy of each method

\begin{tabular}{lcccc}
\hline Method & $\begin{array}{c}\text { Conc. of } \\
\text { CLD } \\
\text { analyzed } \\
(\boldsymbol{\mu g} / \mathbf{m L})\end{array}$ & $\begin{array}{c}\text { Conc. } \\
\text { of CLD } \\
\text { found }^{\mathbf{a}} \\
(\boldsymbol{\mu g} / \mathbf{m L})\end{array}$ & $\begin{array}{c}\text { RSD } \\
(\%)^{\mathbf{b}}\end{array}$ & $\begin{array}{c}\text { Recovery } \\
(\%)\end{array}$ \\
\hline $\boldsymbol{A}$ & & & & \\
Level 1 & 5.1 & 5.2 & 2.6 & 98.1 \\
Level 2 & 7.4 & 7.2 & 3.98 & 97.3 \\
Level 3 & 11.3 & 11.2 & 1.2 & 99.1 \\
$\boldsymbol{B}$ & 1.4 & 1.5 & 2.4 & 94.6 \\
Level 1 & 3.7 & 3.5 & 3.3 & 94.6 \\
Level 2 & 3.7 & 8.1 & 1.5 & 98.7 \\
Level 3 & 8.2 & &
\end{tabular}

\section{Statistical evaluation of the two methods}

Statistical evaluation of was carried out by applying the two methods and the reference method [17] for analysis of $20 \mathrm{mg}$ tablets, with five determinations per method. The results obtained from the proposed methods were compared to those obtained from a standard reference method with respect to accuracy ( $t$ test) and precision ( $F$-test).

The calculated values of student $t$-test and the variance $F$-test (Table 4) were less than the critical values, indicating that there was no significant difference in accuracy and precision between any of the proposed methods and the reference method.

\section{DISCUSSION}

The first developed method (spectrophotometric) was based on selective oxidation of CLD using NBS and methyl orange as chromogenic agents. Studies have shown that NBS is used as a strong bromination agent for alkenes and other organic compounds [14,15].

Table 4: Statistical comparison of results obtained in analysis of $20 \mathrm{mg}$ tablet using the proposed methods, and a reference method

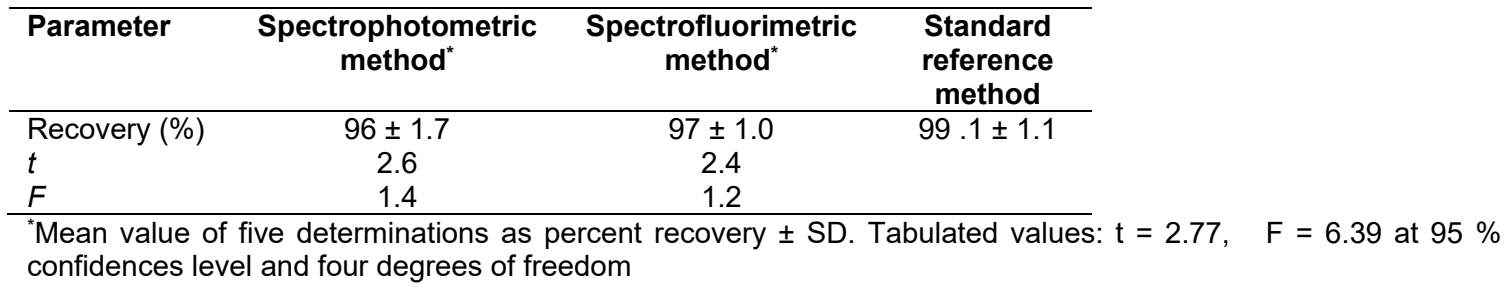


In this study, NBS was used as a bromination agent for the studied drug, with the bromination taking place on the double bond attached to the phenyl group of CLD. The principle of the proposed method involves indirect spectrophotometric analytical method based on the oxidation of CLD with a slight excess of NBS in acidic medium. At the end of the oxidation reaction, a fixed amount of methyl orange dye is added, which is easily bleached by the residual NBS oxidant [16]. As a result, the absorbance of MO dye is directly proportional to the concentration of CLD in the original solution (Figure 7).

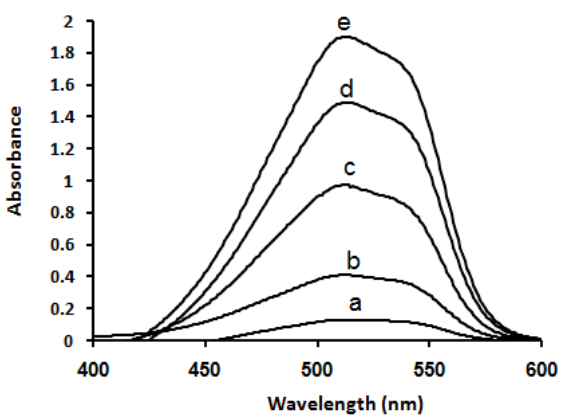

Figure 7: Absorption spectra of CLD. a: 2.5, b: 5.0, c: 7.5 , d: 12 , and e: $18 \mu \mathrm{g} / \mathrm{mL}$, based on calibration curve procedure for method $A$

An alternative method was developed based on oxidation of CLD with Ce (IV) in sulfuric acid, producing highly native fluorescent $\mathrm{Ce}$ (III) which exhibits a maximum emission light at $350 \mathrm{~nm}$ after excitation at $245 \mathrm{~nm}$. Similar spectrofluorimetric methods have been widely applied in pharmaceutical analysis due to their high sensitivity, selectivity and stability [17]. As shown in Figure 8, the emission fluorescence intensities were proportional to the concentration of CLD.

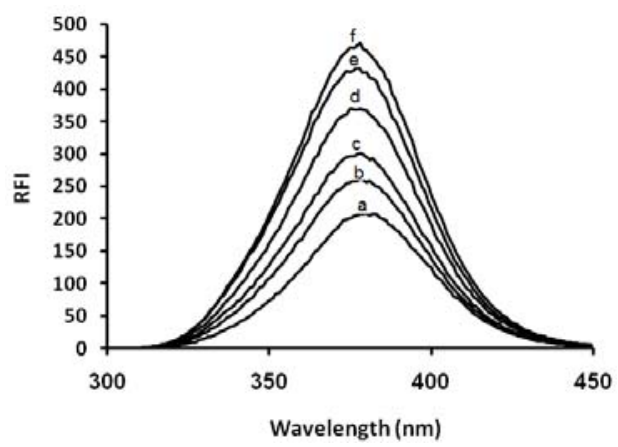

Figure 8: Correlation of the emission spectra of different concentrations of CLD within the linear range of the calibration. a: 0.25 , b: 1.25 , c: 5.0 , d: 7.0 , e: 10.0, and f: $11.2 \mu \mathrm{g} / \mathrm{mL}$, for method $B$

\section{CONCLUSION}

New, simple and sensitive spectrophotometric and spectrofluorimetric methods based on the oxidation of cilnidipine have been developed. These methods used $\mathrm{N}$-bromosucciniamide and Cerium (IV) as oxidants. Both methods have been validated and successfully applied for the determination of CLD as a pure powder and as a single pharmaceutical preparation. Therefore, the new procedures are adequate for routine determination of cilnidipine in bulk and as a drug tablet.

\section{DECLARATIONS}

\section{Acknowledgement}

The authors are thankful to Ruba Zaloum, Amina Nyazi, Maysoun Keswani and Alae Abu Jabal for their assistance in carrying out some measurements.

\section{Conflict of interest}

No conflict of interest is associated with this work.

\section{Contribution of authors}

We declare that this work was done by the authors named in this article and all liabilities pertaining to claims relating to the content of this article will be borne by the authors.

\section{Open Access}

This is an Open Access article that uses a funding model which does not charge readers or their institutions for access and distributed under the terms of the Creative Commons Attribution License (http://creativecommons.org/licenses/by/ 4.0) and the Budapest Open Access Initiative (http://www.budapestopenaccessinitiative.org/rea d), which permit unrestricted use, distribution, and reproduction in any medium, provided the original work is properly credited.

\section{REFERENCES}

1. Sarat K, Ramesh G. The fourth-generation calcium channel blocker: cilnidipine. Ind heart J 2013; 65: 691695.

2. Satoshi H, Oshide K, Joji I, Kazuo E, Kazuyuki S. Comparison of the effects of cilnidipine and amlodipine on ambulatory blood pressure, Hyper Res 2005;28: 1003-1008. 
3. Mohammed M. Spectrophotometric method for the estimation of cilnidipine in bulk and pharmaceutical dosage forms, Orient J Chem 2013; 29: 131-134.

4. Pankaj $P$, Chaudhari A, Bhalerao. Method validation for spectrophotometric estimation of cilnidipine. Int J Pharm Pharm Sci 2013; 4: 96-98.

5. Parihar T, Kotkar M, Mahajan S, Sawant D. Development and validation of UV spectrophotometric methods for the simultaneous estimation of cilnidipine and telmisartan in tablet and bulk dosage form by simultaneous equation and absorbance ratio method. Int J Pharm Integ Life Sci 2014; 2: 59-74.

6. Kokilambigai K, Lakshmi K, Amlesh K, Govind C, Kumar $S$, Mantosh K. Spectrophotometric estimation of cilnidipine in bulk and pharmaceutical dosage form using $n$ - (1-naphthyl) ethylene diamine dihydrochloride, Int J Pharm Pharm Sci 2014; 6: 576-679.

7. Ling-yun HE, Gao-yun HU, ZHOU Yan-bin, Jian-hao LIU. Determination of cilnidipine and its related substances by RP-HPLC, West China J Pharm Sci 2004; 01.

8. Lee $H$, Seo J, Lee H. Development of a liquid chromatography/negative-ion electrospray tandem mass spectrometry assay for the determination of cilnidipine in human plasma and its application to a bioequivalence study. J Chromatog B-Analytical Technologies in the Biomed and life sci 2008; 862: 246-251.

9. Kachave, Ramanlal N, Kale M, Wagh R. Simultaneous Estimation of Cilnidipine and Valsartan by RP-HPLC in Tablet Formulation, Eu. J Anal Chem 2016; 11: 245253.

10. Zhang $X$, Zhai S, Zhao R. Determination of cilnidipine a new calcium antagonist in human plasma using high performance liquid chromatography with tandem mass spectrometric detection Conference: 10th International
Conference on Flow Analysis Location: Porto. Anal Chim Acta 2007; 600: 142-146.

11. Rajeev J, Dhanjai. An Electrochemical Sensor Based on Synergistic Effect of Nano Zinc Oxide-Multiwalled Carbon Nanotubes Hybrid Film for Sensing of Calcium Antagonist Cilnidipine. J Electrochem Soc 2013; 160: 645-652.

12. Mathur NK, Narang CK, Determination of Organic Compounds with N-Bromosuccinamide and Allied Reagents, Academic Press, London, UK, 1975.

13. Mohamed, El Hamd, Sayed M, Derayea, Osama H, Abdelmageed, Hassan F, Askal. Spectrophotometric Method for Determination of Five 1,4-Dihydropyridine Drugs Using N-Bromosuccinimide and Indigo Carmine Dye. Int J Spec 2013; 2:1-8.

14. Basavaiah K, Somashekar BC. Titrimetric and Spectrophotometric Determination of Metoprolol tartrate in Pharmaceuticals Using N-Bromosuccinimide, EJournal of Chemistry 2007; 4: 117-127.

15. Omar MA, Badr El-Din KM, Salem H, Abdelmageed O. Spectrophotometric and spectrofluorimetric methods for determination of certain biologically active phenolic drugs in their bulk powders and different pharmaceutical formulations. Spectrochim Acta Part A. 2018; 192: 108116.

16. International Conference on Harmonization of Technical Requirements for registration of pharmaceuticals for human use, ICH Harmonized Tripartite Guideline. Validation of Analytical Procedures: Text and Methodology, Q2 (R 1), Complementary Guideline on Methodology dated 1996, London, incorporated in November 2005.

17. JN Miller, JC Miller. Statistics and Chemometrics for Analytical Chemistry, Prentice Hall, 4th ed, 2005. 